\title{
La Evaluación de la Escritura a la Finalización de la Escolaridad Primaria según las Pruebas TERCE y ONE
}

\author{
The Writing Assessment at the End of Primary Education \\ according to TERCE and ONE
}

\author{
Verónica Zabaleta * \\ Luis Ángel Roldán \\ María Eugenia Centeleghe \\ Universidad Nacional de La Plata
}

\begin{abstract}
El presente artículo se propone analizar la modalidad que adopta la evaluación de la escritura en dos operativos que indagan los aprendizajes realizados por los estudiantes a la finalización de la escolaridad primaria, que corresponde al sexto año. Nos referimos al Tercer Estudio Regional Comparativo (UNESCO, 2015), organizado por el Laboratorio Latinoamericano de Evaluación de la Calidad de la Educación (LLECE-UNESCO) y el Operativo Nacional de Evaluación (ONE) llevado a cabo en 2013 por la Dirección Nacional de Información y Evaluación de la Calidad Educativa (DiNIECE, 2014) en Argentina. Asimismo, retoma aportes teóricos significativos en la investigación acerca de los procesos implicados en la escritura, presenta los principales resultados obtenidos por los sujetos examinados en los dos estudios mencionados, considerando algunos aspectos centrales de los diseños curriculares del nivel, en el país de referencia. Esto resulta relevante en tanto que el TERCE parte del análisis curricular de los países participantes. Cabe señalar que la indagación de la escritura se ha ido incorporando tardíamente a los programas de evaluación de la calidad educativa, principalmente por la dificultad que conlleva el análisis de las producciones textuales en abordajes a gran escala. Sin embargo, constituye una habilidad central dentro del marco conceptual de "habilidades para la vida" (Atorresi, 2005).
\end{abstract}

Descriptores: Escritura, Evaluación, Escolaridad primaria, Calidad educativa, Operativo.

This paper aims to analyze the form that takes the writing assessment in two campaigns that explore students learning at the end of primary education, which corresponds to the sixth year. We are referring to the Third Regional Comparative Study (UNESCO, 2015), organized by the Latin American Laboratory for Assessment of the Quality of Education (LLECE-UNESCO) and the National Campaign for Evaluation (ONE) conducted in 2013 by the National Directorate for Information and Assessment of the Quality of Education (DiNIECE, 2014) in Argentina. Additionally, it takes up theoretical contributions derived from research on the processes involved in writing and presents the main results obtained by the subjects examined in the two aforementioned studies, considering some central aspects of the curricular designs for this level in the reference country. This is relevant as the TERCE starts from the curricular analysis of the participating countries. It should be noted that the investigation about writing has been belatedly incorporated to the educational quality assessment programs, mainly due to the difficulty of analyzing textual productions in large-scale approaches. However, it is a core skill within the conceptual framework of "life skills" (Atorresi, 2005).

Keywords: Writing, Assessment, Primary education, Quality of education, Campaign.

*Contacto: veronicazabaleta@gmail.com

ISSN: 1696-4713

www.rinace.net/reice/

revistas.uam.es/reice
Recibido: $\quad 16$ de mayo 2016

$1^{\text {a }}$ Evaluación: 30 de junio 2016

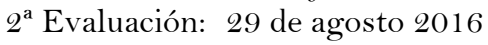

Aceptado: $\quad 15$ de septiembre 2016 
El presente artículo se propone analizar la modalidad que adopta la evaluación de la escritura en dos operativos que indagan los aprendizajes realizados por los estudiantes a la finalización de la escolaridad primaria, que corresponde al sexto año. Nos referimos al Tercer Estudio Regional Comparativo (UNESCO, 2015), organizado por el Laboratorio Latinoamericano de Evaluación de la Calidad de la Educación (LLECE-UNESCO) y el Operativo Nacional de Evaluación (ONE) llevado a cabo en 2013 por la Dirección Nacional de Información y Evaluación de la Calidad Educativa (DiNIECE, 2014) en Argentina. En ambos estudios, se considera que la calidad de la educación es un constructo multidimensional, en el que los aprendizajes constituyen un elemento central aunque no el único. En este sentido, la UNESCO (2007) propone que la educación de calidad implica: eficiencia (buen uso de recursos), equidad (distribución de beneficios educativos), relevancia (que responda a las necesidades de la sociedad) y pertinencia (que responda a las necesidades de los estudiantes) (UNESCO, 2015).

Asimismo, el trabajo retoma aportes teóricos significativos en la investigación acerca de los procesos implicados en la escritura, presenta los principales resultados obtenidos por los sujetos examinados en los dos estudios mencionados, considerando algunos aspectos centrales de los diseños curriculares del nivel, en el país de referencia. Esto resulta relevante en tanto que el TERCE parte del análisis curricular de los países participantes. Esta tarea estuvo a cargo del Instituto Colombiano para la Evaluación de la Educación. Dicho organismo se propuso analizar los documentos oficiales del currículo y otros materiales, identificando elementos comunes para construir los instrumentos de evaluación y permitir la comparación curricular entre países (UNESCO, 2013a).

Cabe señalar que la indagación de la escritura se ha ido incorporando tardíamente a los programas de evaluación de la calidad educativa, principalmente por la dificultad que conlleva el análisis de las producciones textuales en abordajes a gran escala. Sin embargo, constituye una habilidad central dentro del marco conceptual de "habilidades para la vida". Este concepto surge primeramente asociado a las capacidades para el cuidado de la salud, extendiendo luego su significado a otras áreas. Tal como afirma Atorresi (2005) hace referencia a las capacidades - los conocimientos, las habilidades, los valores, las actitudespara enfrentar exitosamente los desafíos diarios de la vida (privada, profesional y social), las situaciones excepcionales, y también para continuar aprendiendo y proyectar un futuro mejor. Esto cobra pleno sentido si se considera que gran parte de los acontecimientos significativos en la vida de los individuos y las sociedades supone algún tipo de documentación escrita (Olson, 1997). Nuestra comprensión del mundo se encuentra cada vez más mediada por la palabra escrita, tanto en su modalidad impresa como digital (UNESCO, 2013b).

\section{La escritura y la producción textual: aportes teóricos}

Uno de los modelos teóricos acerca de la producción escrita de textos más divulgados es la denominada teoría de la redacción como proceso, propuesta por Hayes y Flower (1981) en la década del 80. Estos autores elaboraron un modelo que, en sus sucesivas revisiones, describe determinantes y procesos, cuyas relaciones son complejas.

Entre los determinantes, la memoria a largo plazo y el contexto de producción juegan un papel fundamental. En la memoria a largo plazo están almacenados conocimientos previos de diferente tipo: sobre el tema pero también sobre las dimensiones y convenciones del 
lenguaje escrito (Gombert, 1990, 1992). La redacción está restringida, además, por el contex to de producción, que implica contemplar los objetivos de la escritura, la motivación para escribir, las características del interlocutor al que va destinado el texto y la interpretación del propio escribiente de la tarea de escribir.

En cuanto a los procesos propiamente dichos, Hayes y Flower (1981) señalan tres niveles: planificación, traducción o textualización y revisión, que guardan entre sí interrelaciones complejas y recursivas.

La planificación de un texto toma en consideración los siguientes elementos:

- La tematización de lo que se quiere escribir (sobre qué se va a escribir).

- Los alcances y restricciones con los que se abordará el tema (cuánto se va a escribir sobre ese tema, a partir de la generación de ideas o conocimientos propios o de los que refieran a fuentes de información externa).

- La elección del estilo en función del interlocutor (para quién se va a escribir).

- La organización de lo que se va escribir, conforme a las estructuras textuales que se necesiten (narrativas, expositivas -descripción, comparación, causalidad, resolución, argumentativas).

El proceso de traducción o textualización, también denominado de transcripción, consiste en codificar el mensaje apelando a los conocimientos alfabéticos y extra alfabéticos que rigen las convenciones de la escritura. En el primer caso se trata de conocimientos grafofonéticos, léxicos, ortográficos, sintácticos, semánticos, textuales y pragmáticos. En el segundo del tratamiento de un conjunto de sectores que van desde la puntuación a la organización de la página, pasando por la atención a los espacios en blanco (al inicio de párrafo -sangría, entre palabras, interpárrafos, entre títulos y subtítulos, márgenes, etc.), cifras, etc. (Jaffré, 1988, 1996).

En cuanto al proceso de revisión refiere a la corrección del texto en todas las dimensiones involucradas en la textualización con el objeto de garantizar su coherencia y cohesión, de modo tal que el resultado final suele constituir un nuevo texto (Piacente, 2012). El modelo propuesto por Hayes y Flower (1981) fue revisado y expandido por Hayes (1996) para complementar la descripción de los procesos cognitivos con una amplia discusión del contexto, la motivación, los afectos y la memoria.

$\mathrm{Si}$ bien los tres grandes procesos originales fueron mantenidos, resultaron sustancialmente re-conceptualizados. La planificación fue incluida bajo un nivel más amplio de reflexión, que comprende resolución de problemas. La textualización fue retitulada como producción textual y fue considerablemente elaborada por Chenoweth y Hayes (2001). El proceso original de revisión fue expandido de modo tal de incluir la interpretación textual, subsumida del mismo modo que la reflexión y la producción textual bajo el control de la revisión específica de tareas de esquema (Hayes, 2004).

Además de esos elaborados procesos cognitivos que se atribuyen al individuo existen otros componentes afectivos (propósitos, predisposiciones y creencias), cognoscitivos relativos al conocimiento del escritor proveniente de la memoria a largo plazo (por ej., conocimiento del tópico, género, audiencia) y mnemónicos (memoria de trabajo y memoria a largo plazo). Intervienen además, las características del medio, que comprende por igual al medio físico y social. El medio social involucra la audiencia, los colaboradores y al contexto 
instruccional (McCutchen, 2006). El medio físico incluye el desarrollo del texto y el medio de composición.

El modelo original y su posterior revisión hacen referencia a los escritores expertos. Sin embargo, Bereiter y Scardamaglia (1987) sostienen que la escritura infantil no constituye una versión deficiente de la escritura experta. Proponen dos modelos que intentan precisamente dar cuenta de la diferencia entre expertos y novatos. "Decir el conocimiento", que explica la escritura en etapas tempranas, y "Transformar el conocimiento", que se refiere a los procesos de composición de escritores maduros. "Decir el conocimiento" o "conocimiento contado" (knowledge telling), alude a la modalidad según la cual el escritor para generar un texto, sondea en la memoria de manera simultánea el tópico de la tarea (por ej., "Algo que conozco acerca del futbol es...") o del género (por ej., "Había una vez...") y a medida que escanea en la red de la memoria el conocimiento relacionado, recupera el contenido del texto. "Transformar el conocimiento", en cambio, implica adaptar la información recuperada para la audiencia y los propósitos del escritor. El modelo plantea una interacción entre los problemas retóricos (relacionados con la situación de escritura) y los problemas de contenido. Los escritores expertos son capaces de operar simultáneamente con representaciones mentales de distintos niveles, tales como las estructuras textuales y la intención pragmática del texto (Sánchez Abchi y Borzone, 2010).

En el último cuarto del siglo XX, han aparecido tanto en América como en Europa, otras iniciativas de investigación, que conforman la teoría de la escritura actual (Hayes, 2006). Se trata de las investigaciones sobre el rol de la memoria de trabajo en la escritura, de los estudios sobre la eficacia de la escritura libre y de la propuesta de utilizar la teoría de la actividad como marco para la comprensión del contexto de escritura. La única característica que comparten entre ellas es su potencial para expandir la comprensión de los procesos de escritura. Solo se ofrecerá un panorama sucinto de cada una de ellas.

\subsection{El rol de la memoria en la escritura}

Los psicólogos han introducido el concepto de Memoria de Trabajo para describir las limitaciones que se experimentan en la ejecución de una variedad de tareas que requieren memoria. La memoria de trabajo (es limitada en cuanto el monto de material que puede tomar y a la amplitud de tiempo que puede retenerlo. Comprender cómo diferentes procesos de escritura apelan a los mismos recursos limitados de la memoria de trabajo, puede ayudar a entender cómo cada uno de esos procesos puede interferir a los otros. Baddeley y sus colegas (Baddeley y Hitch, 1974; Gathercole y Baddeley, 1993) propusieron un conocido modelo de memoria de trabajo (de trabajo que tiene almacenes separados para el material verbal y visual. El modelo consiste en tres partes: el bucle o lazo fonológico para almacenar información verbal, la agenda visoespacial para almacenar información visual y el ejecutivo central que, entre otras funciones, administra las otras dos partes.

El bucle fonológico consiste en dos partes; una corresponde al almacén fonológico a corto plazo, que representa el material verbal en un código (auditivo) que declina en pocos segundos. La segunda parte es subvocal, corresponde al proceso de ensayo articulatorio que refresca el material en el almacén a corto plazo. Este modelo de memoria fue considerado por Hayes en 1996, y asimismo dio lugar a otro modelo, el de Kellogg (1999). Ambos guardan algunas diferencias entre si. A grandes rasgos, el primero sostiene que la memoria de trabajo verbal interviene en todos los subprocesos de escritura. El segundo, 
por el contrario, considera que los componentes verbal y visoespacial intervienen diferencialmente en los diferentes subprocesos. La evidencia empírica no es concluyente a ese respecto. Investigaciones posteriores podrán elucidar esa cuestión.

\subsection{Estudios sobre la escritura libre}

Constituye principalmente el uso de determinadas estrategias destinadas a preparar textos, referidas al bosquejo de un borrador y/o de una lista de tópicos y sub tópicos a desarrollar. Tales elementos pueden ser utilizados para guiar la producción de las oraciones formales a ser incluidas en el texto final. Se trata de estrategias primarias de esquema o borrador (outline first strategy). Cuando aparecen dificultades o se descubren nuevas ideas, el borrador se modifica. Pero Hayes (2006) hace una serie de objeciones sujetas a futuros debates: en primer lugar, la ausencia de entrenamiento de los participantes en distintas investigaciones para elaborar un borrador interactivo. En segundo lugar, si eso se hiciera, es cuestionable que el uso de estrategias interactivas para elaborar borradores, incremente o mejore las ideas.

\subsection{La teoría de la actividad como marco para la comprensión del contexto de escritura}

La teoría de la actividad describe las determinaciones que subyacen a las acciones que una persona o grupo de personas toman en relación con el medio en el que tienen lugar. La acción y el medio constituyen un sistema de actividad. Para realizarla, los marcos o esquemas resultan útiles en distintos sentidos:

- Organizan el conocimiento a través de proporcionar un lenguaje común para la comunicación y apoyar los recursos de la memoria.

- Facilitan la adquisición de nuevos conocimientos, a partir de poder destacar elementos comunes, plasmar predicciones y proporcionar las bases para programas de investigación.

En conclusión, según Hayes (2006) esas tres perspectivas sólo forman parte del total de los esfuerzos realizados en las últimas décadas para comprender de manera más acabada los factores sociales y cognitivos implicados en la escritura. No obstante destaca que ilustran la importancia de las teorizaciones que van más allá de lo conocido, así como de la evaluación crítica de las mismas sobre la base de una evidencia empírica cuidadosamente evaluada. Ambas, teoría y evidencia empírica incrementarán la comprensión de la escritura.

Sin embargo a pesar de las contribuciones de los modelos propuestos aparecen algunas limitaciones. Según Fayol (2007) dos de ellas son relevantes:

En primer lugar, las cuestiones relativas al aprendizaje de la escritura han sido ignoradas o poco discutidas. Ciertamente, algunos investigadores han descrito cambios en las estrategias de escritura (Bereiter y Scardamalia, 1987), pero el estudio de los factores susceptibles de intervenir para mejorar la PVE no fue realizado por los autores de los modelos. En segundo lugar, muchas investigaciones se han centrado en la planificación y en la revisión, pero se han descuidado muchos de los problemas de la redacción del texto. (p. 24) 
Sobre este último aspecto, el autor señala además que:

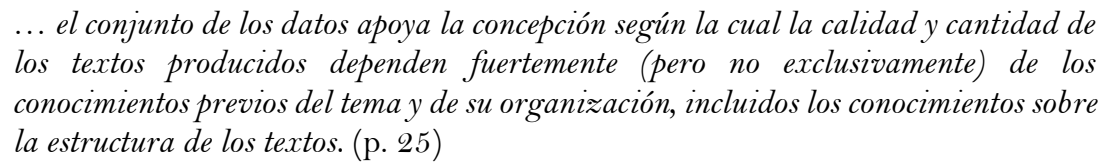

Respecto al proceso de revisión se ha constatado que los niños de edad escolar tienden a no revisar sus escritos o a hacerlo sólo en aspectos superficiales. Sin embargo, la explicitación de las estrategias a utilizar conduce a mejoras en las producciones.

El presente artículo se propone como uno de sus objetivos analizar y comparar la modalidad que adopta la evaluación de la escritura de estudiantes que finalizan la educación primaria (sexto año), en el Tercer Estudio Regional Comparativo (UNESCO, 2015) y en el Operativo Nacional de Evaluación llevado a cabo en Argentina (DiNIECE, 2014). Asimismo, se propone presentar y analizar los principales resultados obtenidos por los sujetos examinados en los dos estudios mencionados, considerando algunos aspectos centrales de los diseños curriculares del nivel, en el país de referencia.

\section{Método}

Para alcanzar los mencionados objetivos se procedió, en primer lugar, a realizar la búsqueda de documentos publicados en las páginas oficiales de las instituciones a cargo de los operativos de evaluación que serían analizados. Se consideraron documentos que permiten caracterizar y contextualizar los operativos y sus predecesores. También aquellos referidos a la modalidad de evaluación de la escritura al finalizar la escolaridad primaria y que, a su vez, presentan los resultados obtenidos por los sujetos examinados.

El TERCE (UNESCO, 2015), llevado a cabo en 2013, constituye una evaluación del desempeño de los estudiantes realizada en América Latina y el Caribe. Está organizado y coordinado por el Laboratorio Latinoamericano de Evaluación de la Calidad de la Educación (LLECE) y se enmarca dentro de las acciones globales de la Oficina Regional de Educación de la UNESCO para América Latina y el Caribe (OREALC/UNESCO Santiago). Sus antecedentes inmediatos son el PERCE (Primer Estudio Regional Comparativo y Explicativo) implementado durante el año 1997 y el SERCE (Segundo Estudio Regional Comparativo y Explicativo) cuya aplicación se realizó durante 2006. Éste último se toma brevemente en consideración en el apartado de resultados ya que es el primero en el que se incluye la evaluación de la escritura.

El TERCE evalúa el desempeño alcanzado por estudiantes latinoamericanos de $3^{\circ}$ y $6^{\circ}$ grados de Educación Primaria en Lectura, Escritura y Matemática, mientras que la evaluación de Ciencias se lleva a cabo sólo en $6^{\circ}$ grado de Educación Primaria. Asimismo, recoge información sobre los estudiantes y sus familias, los docentes, los directores y las escuelas, lo que permite identificar y comprender qué factores inciden en los desempeños estudiantiles. El estudio cuenta con la participación de quince países y un estado subnacional. Argentina participó del mismo y fueron evaluados aproximadamente 3.700 estudiantes de $3^{\circ}$ grado y un número análogo de $6^{\circ}$ grado.

En Argentina, los operativos de evaluación comenzaron en el año 1993, evaluándose las áreas de lengua y matemática en alumnos de séptimo grado y quinto año del secundario. Inicialmente este operativo dependía del Ministerio de Educación hasta que en el año 2001 
se crea la Dirección Nacional de Información y Evaluación de la Calidad Educativa, organismo descentrado de dicho Ministerio (DiNIECE, 2001, 2003).

A partir del Plan de Acciones de Evaluación de Componentes de la Calidad Educativa aprobado por el Consejo Federal de Educación en el año 2010, se consideran los desempeños de los estudiantes como un indicador de la calidad educativa, es decir, de la calidad de los aprendizajes que promueve y/o posibilita un sistema educativo y aún una institución. Sin embargo, es necesario considerar también otras dimensiones como, por ejemplo, los niveles de inclusión o exclusión (DiNIECE, 2010).

El ONE 2010 se instrumentó en una muestra de alumnos de $3^{\circ}$ y $6^{\circ}$ grados de Educación Primaria (5400 escuelas y aproximadamente 70.000 alumnos) y de $2^{\circ} / 3^{\circ}$ año $(1.740$ escuelas y 34.820 alumnos) de Educación Secundaria. Además en el nivel secundario se aplicó a todos los alumnos del último año $\left(5^{\circ}\right.$ o $6^{\circ}$ año). Es decir, que tuvo carácter censal en cuatro áreas de conocimiento: lengua, matemática, ciencias naturales y ciencias sociales (8.889 escuelas de todo el país y 280.000 estudiantes) Se utilizan pruebas referidas al criterio. Las pruebas consideran el desempeño de los estudiantes a partir de su comparación con un criterio establecido antes de aplicar las evaluaciones. Son los diseños curriculares y los núcleos de aprendizaje prioritario (NAP) los que constituyen referentes de la evaluación.

Los contenidos y capacidades evaluados no corresponden a un año escolar ya que lo que se examina es la trayectoria educativa. Las áreas evaluadas son Lengua, Matemática, Ciencias Naturales y Ciencias Sociales. El estudio no sólo consiste en la aplicación de pruebas para medir logros de aprendizaje, sino también de cuestionarios para comprender el contexto y las circunstancias bajo las cuales se da el aprendizaje.

En el análisis llevado a cabo en este trabajo se focalizó en lo relativo a la escritura como una de las áreas examinadas, considerándose las dimensiones evaluadas, y en los resultados obtenidos por Argentina en ambos operativos. Se consideraron aportes teóricos derivados de investigaciones sobre la temática y se incorporaron algunas reflexiones vinculadas a los núcleos de aprendizaje prioritarios y a los diseños curriculares desarrollados en el país de referencia en los últimos años (DGCyE, 2008; NAP, 2005).

\section{Resultados}

\subsection{El Tercer Estudio Regional Comparativo y Explicativo (TERCE): características de la evaluación del desempeño en escritura de los alumnos de $\sigma^{o}$ grado de Educación Primaria}

Para evaluar los desempeños de los estudiantes, tanto el SERCE como el TERCE utilizan pruebas referidas a contenidos comunes en los currículos oficiales de los países de la región y al enfoque de habilidades para la vida promovido por la UNESCO. Esta Organización considera que la escuela debe promover conocimientos, habilidades, valores y actitudes que sirvan a los estudiantes para participar activamente en la sociedad, como individuos y como ciudadanos. El establecimiento de los contenidos comunes se llevó a cabo a través del análisis de los currículos de cada país, de los principales textos escolares y los instrumentos de evaluación que se utilizan en los distintos países participantes del estudio.

En el año 2010 se publica un reporte que presenta la modalidad de evaluación y los resultados obtenidos en escritura por los estudiantes en el SERCE (UNESCO, 2010). La 
consigna utilizada para la evaluación de la escritura en alumnos de sexto grado en dicho operativo solicita la producción de un texto que se publicará en una enciclopedia. Se trabaja con dos cuadernillos: en un caso el tema es el perro y en otro el pan. Se especifican tres pasos que se corresponden con los procesos de planificación, revisión y textualización. En primer lugar solicita completar un borrador que se presenta en la forma de tabla donde las columnas indican subtemas sobre el tema general: características físicas, alimentación, costumbres y relación con las personas, cuando el escrito tiene por tema el perro; y aspecto exterior, ingredientes, modo de preparación y modo de consumo, cuando el tema es el pan. En el segundo paso se dan sugerencias para la revisión del borrador. En tercer lugar se solicita la transformación del borrador en texto y la elaboración de un título.

Los textos pedidos en sexto grado son descripciones enciclopédicas y la situación comunicativa se caracteriza por ser escrita y formal. Respecto a la extensión de los textos se solicita expandir cuatro ideas complejas, es decir, no se sigue el criterio más clásico de solicitar determinada cantidad de palabras o líneas (renglones). Los modelos teóricos subyacentes a la evaluación de la escritura son el modelo procesual cognitivo de Hayes y Flower (1981), el modelo de expertos y novatos (Bereiter y Scardamalia, 1987), ambos surgidos de la Psicología Cognitiva, y el modelo contextual que retoma ideas de Vigotsky (1995, 2006) y Bajtin (1982).

Se calcularon la frecuencia y los porcentajes de los indicadores de la mayor parte de los aspectos evaluados; en otros casos se calcularon medias y se combinaron frecuencias y porcentajes entre aspectos. Para todos los índices o aspectos evaluados se calculó, además, el valor de la diferencia entre países: si esta es estadísticamente significativa -y positiva o negativa para un país en relación con otro- o si no lo es. Los aspectos evaluados en cada grado se informan en relación con cada participante, con el puntaje promedio de los países y el puntaje promedio del total de América Latina y el Caribe. En la evaluación de las producciones se consideraron diferentes aspectos, tal como se especifican en la tabla 1.

El TERCE modifica varios aspectos de la modalidad de evaluación definida por el SERCE. La prueba de escritura consiste en una tarea en la que el estudiante debe elaborar un texto: una carta a un amigo, en tercer grado, y una carta a un directivo de la escuela, en sexto grado. La consigna en sexto grado, tramo del trayecto educativo considerado en el presente trabajo, fue la siguiente:

"En tu escuela van a construir un nuevo espacio para que los estudiantes puedan reunirse a conversar y recrearse. Sin embargo, aún no se han puesto de acuerdo sobre qué construir.

Hay dos propuestas muy distintas: hacer una plaza con pasto y juegos o una cafetería con mesas y sillas.

Para tomar la mejor decisión, la presidenta del Centro de Padres ha pedido a cada curso que entregue su opinión en una carta, en la que den buenas razones que apoyen su elección.

Tú fuiste seleccionado por tu curso para redactar esta carta.

Escribe una carta a la presidenta del Centro de Padres diciendo qué propuesta escogieron y dando buenos motivos de por qué esa propuesta es la mejor. Usa lenguaje formal. (UNESCO, 2015, p. 123) 
Tabla 1. Aspectos evaluados en la prueba de escritura del SERCE ( $6^{\circ}$ grado de EP)

\begin{tabular}{|c|c|c|c|}
\hline \multirow[b]{2}{*}{ ASPECTOS BÁSICOS } & \multirow[b]{2}{*}{$\begin{array}{l}\text { ASPECTOS EN EL } \\
\text { PROCESO DE } \\
\text { ESCRITURA }^{1}\end{array}$} & \multicolumn{2}{|c|}{ ASPECTOS ESTUDIADOS EN EL TEXTO FINAL } \\
\hline & & $\begin{array}{c}\text { Referidos a todo } \\
\text { escrito }^{2}\end{array}$ & $\begin{array}{c}\text { Referidos a todo } \\
\text { escrito que es un } \\
\text { texto } \\
\end{array}$ \\
\hline $\begin{array}{l}\text { - Escritura o prueba } \\
\text { en blanco. } \\
\text { - Escritura sólo del } \\
\text { borrador o sólo del } \\
\text { texto. } \\
\text { - Mantenimiento del } \\
\text { tema y la } \\
\text { estructura entre el } \\
\text { borrador y el texto } \\
\text { definitivo. } \\
\text { - Escritos en la } \\
\text { lengua pedida. } \\
\text { - Escritura de textos } \\
\text { y no textos. }\end{array}$ & $\begin{array}{l}\text { - Adecuación del } \\
\text { tema, tipo textual y } \\
\text { situación } \\
\text { comunicativa. } \\
\text { - Mantenimiento y } \\
\text { aumento de ideas } \\
\text { entre el plan inicial } \\
\text { y la versión final. } \\
\text { - Funciones } \\
\text { comunicativas del } \\
\text { borrador y del } \\
\text { texto. }\end{array}$ & $\begin{array}{l}\text { - Caligrafía. } \\
\text { - Distribución y } \\
\text { promedio de } \\
\text { palabras escritas. } \\
\text { - Distribución y } \\
\text { máximo de palabras } \\
\text { que constituyen } \\
\text { errores de léxico. } \\
\text { - Promedio y } \\
\text { máximo de palabras } \\
\text { que presentan } \\
\text { errores de } \\
\text { ortografía (solo en } \\
\text { sexto). }\end{array}$ & $\begin{array}{l}\text { - Coherencia en el } \\
\text { título. } \\
\text { - Coherencia en la } \\
\text { distribución de la } \\
\text { información. } \\
\text { - Coherencia en la } \\
\text { progresión de la } \\
\text { información. }\end{array}$ \\
\hline
\end{tabular}

En la evaluación de las producciones textuales se utilizó una rúbrica analítica que permitió asignar niveles de desempeño a cada uno de los aspectos evaluados. Es decir, que los textos producidos por los estudiantes evaluados fueron puntuados con una rúbrica que contiene nueve indicadores agrupados en tres dimensiones. Cada uno de estos indicadores tiene, a su vez, cuatro niveles de desempeño, los que se caracterizan en las tablas 2, 3 y 4 .

Las tres dimensiones consideradas fueron las siguientes:

Dimensión discursiva. Alude a aquellas marcas en el texto ligadas a la situación comunicativa. Incluye la consideración de tres indicadores:

- Propósito, secuencia y adecuación a la consigna. El propósito refiere a la actividad verbal asociada a la consigna que se presenta, en este caso, implicaría opinar. La secuencia se vincula a lo que puede denominarse el tipo textual. La secuencia predominante es la argumentativa. Finalmente, la adecuación a la consigna implica la adecuación temática, tanto de la opinión como de sus argumentos.

- Género. Este indicador se refiere a la habilidad de participar en un modelo socialmente establecido de textos que resulta adecuado para resolver el problema comunicativo. Bajtín (1982) plantea las categorías de enunciado y género discursivo. El enunciado es la unidad concreta de la comunicación. En relación con una práctica social determinada, los enunciados adoptan formas relativamente estables que constituyen los géneros discursivos. En cada área de actividad, por ejemplo la educación, la justicia, el periodismo, la literatura, etc., pueden verificarse formas particulares de uso de la lengua, los géneros (Silvestri, 2001). Las categorías de este indicador buscan caracterizar los usos incipientes de marcadores funcionales al propósito comunicativo planteado 
(presencia de saludo, marcas de segunda persona, orientación a un destinatario).

- Registro. Remite a la adecuación a la situación comunicativa escrita y formal. Se contemplan las marcas de informalidad (transgresiones a la situación formal asimétrica, que incluyen el uso de jergas, el tratamiento en segunda persona informal a la autoridad y el uso de insultos o malas palabras) y las marcas de oralidad.

Tabla 2. Caracterización de los niveles de desempeño en cada indicador de la dimensión discursiva

\begin{tabular}{|c|c|c|c|}
\hline & $\begin{array}{l}\text { PROPÓSITO, SECUENCIA } \\
\text { Y ADEC. A LA CONSIGNA }\end{array}$ & GÉNERO & REGISTRO \\
\hline $\begin{array}{c}\text { Nivel } \\
\text { I }\end{array}$ & $\begin{array}{l}\text { El texto no resuelve el } \\
\text { problema comunicativo } \\
\text { planteado, porque articula } \\
\text { una secuencia distinta a la } \\
\text { pedida en la consigna. }\end{array}$ & $\begin{array}{l}\text { La carta presenta el cuerpo } \\
\text { más alguna de las } \\
\text { siguientes fórmulas sin } \\
\text { marcas de apelación al } \\
\text { destinatario: encabezado, } \\
\text { cierre, firma personal o } \\
\text { grupal. O bien, el texto no } \\
\text { es una carta sino que otro } \\
\text { género. }\end{array}$ & $\begin{array}{l}\text { El texto presenta cuatro o } \\
\text { más marcas de } \\
\text { informalidad u oralidad. O } \\
\text { bien, todo el texto está } \\
\text { escrito en otro registro, ya } \\
\text { sea porque solo hay } \\
\text { evidencia de inadecuación } \\
\text { a la situación formal } \\
\text { asimétrica o porque se } \\
\text { reproduce un texto oral } \\
\text { (un diálogo o el turno de } \\
\text { un diálogo). }\end{array}$ \\
\hline $\begin{array}{c}\text { Nivel } \\
\text { II }\end{array}$ & $\begin{array}{l}\text { Explicita solo una opinión } \\
\text { o solo los fundamentos a } \\
\text { partir de la consigna. O } \\
\text { bien, escoge y/o } \\
\text { fundamenta dos opiniones } \\
\text { a partir de la consigna, sin } \\
\text { inclinarse por ninguna. O } \\
\text { bien, explicita y } \\
\text { fundamenta una opinión } \\
\text { distinta de la pedida en la } \\
\text { consigna. }\end{array}$ & $\begin{array}{l}\text { La carta presenta un cuerpo } \\
\text { más uno de los siguientes } \\
\text { elementos con marcas de } \\
\text { apelación al destinatario: } \\
\text { encabezado, cierre, firma } \\
\text { personal o grupal. O bien, } \\
\text { la carta presenta solo un } \\
\text { cuerpo, pero es posible } \\
\text { identificar la orientación } \\
\text { hacia un destinatario por la } \\
\text { presencia de marcas de } \\
\text { apelación en él. }\end{array}$ & $\begin{array}{l}\text { El texto presenta hasta } \\
\text { tres marcas de } \\
\text { informalidad u oralidad. }\end{array}$ \\
\hline $\begin{array}{c}\text { Nivel } \\
\text { III }\end{array}$ & $\begin{array}{l}\text { El texto explicita una } \\
\text { opinión a partir de la } \\
\text { consigna y solo enuncia el } \\
\text { o los fundamentos. }\end{array}$ & $\begin{array}{l}\text { La carta presenta un cuerpo } \\
\text { más dos de los siguientes } \\
\text { elementos con marcas de } \\
\text { apelación al destinatario: } \\
\text { encabezado, cierre, firma } \\
\text { personal o grupal. }\end{array}$ & $\begin{array}{l}\text { El texto presenta una } \\
\text { marca de informalidad y } \\
\text { una marca de oralidad } \\
\text { (hasta una de cada una). }\end{array}$ \\
\hline $\begin{array}{l}\text { Nivel } \\
\text { IV }\end{array}$ & $\begin{array}{l}\text { El texto explicita una } \\
\text { opinión a partir de la } \\
\text { consigna y al menos un } \\
\text { fundamento desarrollado } \\
\text { que la sustente. }\end{array}$ & $\begin{array}{l}\text { La carta presenta al menos } \\
\text { los siguientes elementos } \\
\text { con marcas de apelación al } \\
\text { destinatario: encabezado: } \\
\text { fórmula de saludo o } \\
\text { vocativo inicial, cuerpo, } \\
\text { cierre: fórmula de despedida } \\
\text { apelativa, firma personal o } \\
\text { grupal. }\end{array}$ & $\begin{array}{l}\text { El texto presenta un } \\
\text { registro adecuado a la } \\
\text { situación formal asimétrica } \\
\text { y no existen marcas de } \\
\text { oralidad en el texto. }\end{array}$ \\
\hline
\end{tabular}


Dimensión textual. Contempla elementos de estructura interna del texto. Considera tres indicadores:

- Coherencia global que refiere a la continuidad y progresión temáticas.

- Concordancia, la que se observa en el uso de la concordancia intraoracional (concordancia nominal y verbal).

- Cohesión. Este indicador busca dar cuenta del uso de diversos mecanismos de orden gramatical, tanto a nivel del texto como de la oración, que permiten asignar unidad al texto, ya sea por la mantención de los referentes, por la completitud de las oraciones o por la relación entre diferentes ideas. Según Molinari Marotto (1996):

...la cohesión de un texto está dada por la presencia de ex-presiones cuya interpretación depende de la interpretación de otras expresiones del texto, sirviendo estas co-interpretaciones para entrelazar las oraciones. Dichas expresiones permiten evitar repeticiones de palabras y mantener la continuidad referencial (es decir, la continuidad de aquello a que el texto se refiere, su tema). (p. 125)

Tabla 3. Caracterización de los niveles de desempeño en cada indicador de la dimensión textual

\begin{tabular}{|c|c|c|c|}
\hline & COHERENCIA GLOBAL & CONCORD. ORACIONAL & COHESIÓN TEXTUAL \\
\hline $\begin{array}{c}\text { Nivel } \\
\text { I }\end{array}$ & $\begin{array}{l}\text { No se puede determinar un } \\
\text { tema central. O bien, } \\
\text { ningún fundamento se } \\
\text { relaciona con la tesis. }\end{array}$ & $\begin{array}{l}\text { La concordancia } \\
\text { oracional se pierde } \\
\text { frecuentemente en el } \\
\text { texto, lo que interfiere } \\
\text { gravemente en su } \\
\text { comprensión. Se } \\
\text { presentan } 5 \text { o más } \\
\text { errores. }\end{array}$ & $\begin{array}{l}\text { El texto no está } \\
\text { correctamente cohesionado, } \\
\text { debido a que presenta } \\
\text { problemas de referencia u } \\
\text { omisión de palabras o frases } \\
\text { necesarias para su } \\
\text { comprensión y, además, } \\
\text { problemas de conexión. }\end{array}$ \\
\hline
\end{tabular}

\begin{tabular}{|c|c|c|c|}
\hline $\begin{array}{l}\text { Nivel } \\
\text { II }\end{array}$ & $\begin{array}{l}\text { El texto presenta varios } \\
\text { temas, aunque es posible } \\
\text { inferir un tema central. O } \\
\text { bien, existen digresiones } \\
\text { ocasionales en el texto y, } \\
\text { además, el tema se estanca, } \\
\text { porque se repite un mismo } \\
\text { fundamento. }\end{array}$ & $\begin{array}{l}\text { La concordancia } \\
\text { oracional se mantiene } \\
\text { ocasionalmente en el } \\
\text { texto. Se presentan } \\
\text { entre } 3 \text { y } 4 \text { errores. }\end{array}$ & $\begin{array}{l}\text { El texto está cohesionado, } \\
\text { aunque: se pierden referentes, } \\
\text { se omiten palabras. }\end{array}$ \\
\hline $\begin{array}{c}\text { Nivel } \\
\text { III }\end{array}$ & $\begin{array}{l}\text { El tema se mantiene a lo } \\
\text { largo del texto, a pesar de } \\
\text { que pueda haber algunas } \\
\text { digresiones ocasionales. O } \\
\text { bien, el tema se mantiene } \\
\text { sin digresiones, pero se } \\
\text { estanca porque se repite un } \\
\text { mismo fundamento. }\end{array}$ & $\begin{array}{l}\text { La concordancia } \\
\text { oracional se mantiene } \\
\text { habitualmente en el } \\
\text { texto. Se presentan } \\
\text { entre } 1 \text { y } 2 \text { errores. }\end{array}$ & $\begin{array}{l}\text { El texto está cohesionado, } \\
\text { aunque se omiten o se usan } \\
\text { incorrectamente: nexos, } \\
\text { intraoracionales, conectores. }\end{array}$ \\
\hline $\begin{array}{l}\text { Nivel } \\
\text { IV }\end{array}$ & $\begin{array}{l}\text { El tema central se } \\
\text { mantiene y se desarrolla } \\
\text { mediante subtemas } \\
\text { vinculados al tema central } \\
\text { a lo largo del texto. }\end{array}$ & $\begin{array}{l}\text { La concordancia } \\
\text { oracional se mantiene a } \\
\text { lo largo del texto. No se } \\
\text { presentan errores. }\end{array}$ & $\begin{array}{l}\text { El texto está cohesionado } \\
\text { porque: se mantienen los } \\
\text { referentes, no se omiten } \\
\text { palabras, no se omiten y se } \\
\text { usan correctamente nexos } \\
\text { intraoracionales y } \\
\text { conectores. No hay } \\
\text { contradicciones temáticas. }\end{array}$ \\
\hline
\end{tabular}

Fuente: Adaptado de UNESCO (2015). 
Dimensión convenciones de legibilidad. Alude a convenciones propias de la comunicación escrita que dan cuenta del dominio del código. Se plantea como criterio, no la normatividad sino la comprensibilidad del texto. Considera tres indicadores:

- Ortografía literal inicial. Se intenta dar cuenta del grado de conciencia de las convenciones que rigen lo escrito y de sus normas básicas. En la medida en que se considera un nivel inicial de dominio de reglas ortográficas solo se observa la concordancia entre el grafema y el fonema con el que se le asocia.

- Segmentación de palabras. La segmentación lexical a nivel del texto escrito refiere al proceso de dividir lo escrito en palabras u otras unidades significativas. Se diferencian dos tipos de segmentaciones no convencionales de palabras: las hiposegmentaciones (uniones no convencionales) y las hipersegmentaciones (separaciones arbitrarias) (Querejeta, 2007).

- Puntuación. En este indicador también se contempla un dominio inicial de las marcas propias del código escrito. Se considera el uso de la coma, del punto seguido y del punto al final del texto.

Piacente (2012) afirma que el lenguaje escrito no se reduce al sistema de escritura y que involucra también conocimiento sobre las marcas extra alfabéticas, entre las que señala el dominio de los signos de puntuación, el tratamiento de los espacios en blanco, la ortografía, el reconocimiento de los diferentes alógrafos, entre otros. Estas marcas extra alfabéticas estarían en el TERCE representadas por el dominio "convenciones de legibilidad".

\subsection{Desempeño en escritura de los alumnos argentinos de $6^{\circ}$ grado en el TERCE}

Un primer análisis considera el promedio de las puntuaciones obtenido por cada país, en una escala de 1 a 4 puntos, en comparación con la media obtenida por el conjunto de los países participantes.

La puntuación promedio obtenida por los estudiantes argentinos en la prueba de escritura $(3,39)$ es significativamente superior a la obtenida por el promedio de países $(3,19)$. Dentro de este grupo se encuentran además Chile, Costa Rica, Guatemala y México.

Asimismo se considera la variabilidad de las puntuaciones, lo que informa acerca de las desigualdades en el desempeño de los estudiantes de cada país. Los datos indican que la distancias entre los percentiles 10 y 90 de los países evaluados oscila entre 2,89 y 3,52 puntos.

En una segunda sección, el informe presenta los puntajes promedios obtenidos por los distintos países en cada una de las tres dimensiones analizadas y se los compara con el promedio regional.

Los países participantes obtienen los mejores puntajes en la dimensión textual, luego en convenciones de legibilidad y, finalmente, en la dimensión discursiva.

Argentina obtiene puntuaciones que superan significativamente el promedio regional en las tres dimensiones. Comparte análogos resultados con países tales como Chile y Costa Rica. 
Tabla 4. Caracterización de los niveles de desempeño en cada indicador de la dimensión convenciones de legibilidad

\begin{tabular}{|c|c|c|c|}
\hline & $\begin{array}{c}\text { ORTOGRAFÍA LITERAL } \\
\text { INICIAL }\end{array}$ & $\begin{array}{c}\text { SEGMENTACIÓN DE } \\
\text { PALABRAS }\end{array}$ & Puntuación \\
\hline $\begin{array}{l}\text { Nivel } \\
\text { I }\end{array}$ & $\begin{array}{l}\text { El texto presenta } 8 \text { o } \\
\text { más errores con } \\
\text { asociación sonido- } \\
\text { grafema. El texto } \\
\text { registra } 3 \text { o más } \\
\text { errores sin asociación } \\
\text { sonido-grafema. }\end{array}$ & $\begin{array}{l}\text { La mayoría de las } \\
\text { palabras del texto no } \\
\text { está correctamente } \\
\text { segmentada. Se } \\
\text { presentan } 3 \text { o más } \\
\text { errores. }\end{array}$ & $\begin{array}{l}\text { Se presentan los tres siguientes } \\
\text { errores: interrumpir una oración } \\
\text { con un punto seguido, ausencia } \\
\text { de coma en una enumeración, } \\
\text { ausencia del punto final. O bien, } \\
\text { el texto no presenta puntuación. }\end{array}$ \\
\hline $\begin{array}{l}\text { Nivel } \\
\text { II }\end{array}$ & $\begin{array}{l}\text { El texto registra entre } \\
5 \text { y } 7 \text { errores con } \\
\text { asociación sonido- } \\
\text { grafema. El texto } \\
\text { registra } 2 \text { errores sin } \\
\text { asociación sonido- } \\
\text { grafema. }\end{array}$ & $\begin{array}{l}\text { Las palabras del texto } \\
\text { ocasionalmente están } \\
\text { correctamente } \\
\text { segmentadas. Se } \\
\text { presentan } 2 \text { errores. }\end{array}$ & $\begin{array}{l}\text { Se presentan dos de los } \\
\text { siguientes errores: interrumpir } \\
\text { una oración con un punto } \\
\text { seguido, ausencia de coma en } \\
\text { una enumeración, ausencia del } \\
\text { punto final. }\end{array}$ \\
\hline $\begin{array}{l}\text { Nivel } \\
\text { III }\end{array}$ & $\begin{array}{l}\text { El texto registra entre } \\
2 \text { y } 4 \text { errores con } \\
\text { asociación sonido- } \\
\text { grafema. El texto } \\
\text { registra } 1 \text { error sin } \\
\text { asociación sonido- } \\
\text { grafema. }\end{array}$ & $\begin{array}{l}\text { Las palabras del texto } \\
\text { habitualmente están } \\
\text { correctamente } \\
\text { segmentadas. Se } \\
\text { presenta } 1 \text { error. }\end{array}$ & $\begin{array}{l}\text { Se presenta uno de los } \\
\text { siguientes errores: interrumpir } \\
\text { una oración con un punto } \\
\text { seguido, ausencia de coma en } \\
\text { una enumeración, ausencia del } \\
\text { punto final. }\end{array}$ \\
\hline $\begin{array}{l}\text { Nivel } \\
\text { IV }\end{array}$ & $\begin{array}{l}\text { El texto registra } 1 \\
\text { error con asociación } \\
\text { entre sonido y grafema. } \\
\text { El texto no presenta } \\
\text { errores sin asociación } \\
\text { entre sonido y grafema. }\end{array}$ & $\begin{array}{l}\text { Todas las palabras del } \\
\text { texto están } \\
\text { correctamente } \\
\text { segmentadas. No se } \\
\text { presentan errores. }\end{array}$ & $\begin{array}{l}\text { Se presentan los siguientes usos } \\
\text { de puntuación de manera } \\
\text { adecuada: punto seguido, coma } \\
\text { en una enumeración, punto final. }\end{array}$ \\
\hline
\end{tabular}

Fuente: Elaboración propia a partir de UNESCO (2015).

Tabla 5. Puntuaciones promedio obtenidas por los estudiantes de $6^{\circ}$ año de Argentina y por el total de países participantes en los tres dominios de la prueba de escritura

\begin{tabular}{lccc}
\hline \multicolumn{1}{c}{ PAís } & $\begin{array}{c}\text { DoMINIO } \\
\text { DISCURSIVO }\end{array}$ & DoMinio TEXTUAL & $\begin{array}{c}\text { CoNVENCIONES DE } \\
\text { LEGIBILIDAD }\end{array}$ \\
\hline Argentina & 3,27 & 3,53 & 3,34 \\
Promedio Países & 3,01 & 3,37 & 3,21 \\
\hline Fuente: Elaboración propia a partir de UNESCO $(2015)$. &
\end{tabular}

Fuente: Elaboración propia a partir de UNESCO (2015).

En una tercera sección se considera el porcentaje de sujetos que, en las tres dimensiones evaluadas, se sitúan en cada nivel de desempeño (tabla 6).

Tabla 6. Porcentaje de sujetos argentinos y del total de países participantes situados en cada nivel según los tres dominios examinados

\begin{tabular}{lcccrrr}
\hline & \multicolumn{2}{c}{ Dominio DISCURsivo } & \multicolumn{2}{c}{ Dominio TEXTUAL } & \multicolumn{2}{c}{$\begin{array}{c}\text { CONVENCIONES DE } \\
\text { LEGIBILIDAD }\end{array}$} \\
\cline { 2 - 7 } & Argentina & $\begin{array}{c}\text { Total } \\
\text { países }\end{array}$ & Argentina & $\begin{array}{c}\text { Total } \\
\text { países }\end{array}$ & Argentina & $\begin{array}{c}\text { Total } \\
\text { países }\end{array}$ \\
\hline Nivel I & 10,4 & 15,6 & 1,9 & 4,0 & 10,4 & 13,9 \\
Nivel II & 10,0 & 15,3 & 8,1 & 10,8 & 6,2 & 7,5 \\
Nivel III & 22,1 & 22,0 & 24,8 & 29,4 & 22,9 & 22,5 \\
Nivel IV & 57,5 & 47,2 & 65,3 & 55,8 & 60,6 & 56,1 \\
\hline
\end{tabular}

Fuente: Elaboración propia a partir de UNESCO (2015). 
El Informe señala que según los resultados obtenidos por el conjunto de los países en la prueba de escritura, los textos elaborados por los estudiantes suelen presentar altos grados de coherencia y orden gramatical. El mayor desafío se sitúa en la dimensión discursiva. Esto parece, en principio, contradecir los énfasis que se desprenden del análisis de los diseños curriculares que promueven un uso social comunicativo de las habilidades de escritura de textos. En Argentina, el área de Prácticas del Lenguaje explicita la importancia de iniciar los procesos de aprendizaje precisamente por las prácticas mismas concebidas como sociales y no por los tradicionales contenidos lingüísticos escolares.

Respecto de la variabilidad de puntajes dentro de cada país, se observa que existen grandes diferencias entre los puntajes asociados a los percentiles más altos y los más bajos respecto de la distribución de logro de aprendizaje.

Si bien Argentina presenta buenos resultados en la evaluación de la escritura comparativamente respecto de los obtenidos en la región, al igual que sucede en la mayoría de los países participantes se observa una importante variabilidad entre los desempeños de los estudiantes con alto y bajo rendimiento.

\subsection{Características de la evaluación del desempeño en escritura de los alumnos de $6^{o}$ grado de Educación Primaria en el ONE en Argentina}

En el Operativo Nacional de Evaluación 2013 (ONE) se evaluó por primera vez, en el área de Lengua, la producción escrita a la finalización de la escolaridad primaria y secundaria. En este trabajo nos centraremos principalmente en la modalidad de evaluación y en los resultados que corresponden a sexto grado/año de la Educación Primaria.

La prueba de actividades se aplicó a 44.105 alumnos. De esta muestra probabilística de ítems abiertos del ONE 2013, se seleccionó una muestra aleatoria de 800 estudiantes con representatividad nacional para evaluar la producción escrita de los alumnos de sexto año.

Se definieron para el conjunto de las pruebas tres 3 niveles generales de desempeño: alto, medio y bajo (tabla 7 ).

Tabla 7. Descripción de los niveles de desempeño en el ONE 2013

\begin{tabular}{cc}
\hline NIVEL & DESCRIPCIÓN \\
\hline Alto & $\begin{array}{l}\text { Este nivel implica un desempeño destacado en el dominio del conjunto de contenidos y } \\
\text { capacidades cognitivas evaluadas y esperables, según los documentos curriculares } \\
\text { jurisdiccionales y los NAP considerados como referentes. }\end{array}$ \\
\hline Medio & $\begin{array}{l}\text { Este nivel implica un desempeño satisfactorio en el dominio del conjunto de } \\
\text { contenidos y capacidades cognitivas evaluadas y esperables, según los documentos } \\
\text { curriculares jurisdiccionales y los NAP considerados como referentes. }\end{array}$ \\
\hline Bajo $\quad \begin{array}{l}\text { Este nivel implica un desempeño elemental o poco satisfactorio en el dominio del } \\
\text { documentos curriculares jurisdiccionales y los NAP considerados como referentes. }\end{array}$ \\
\hline Fuente: Elaboración propia a partir de DiNIEC (2014). \\
En el Operativo, se define a la escritura como práctica social e individual. Permite la \\
comunicación social, la administración, la comunicación al tiempo que constituye un \\
proceso cognitivo complejo. La incorporación tardía de la escritura en los procesos de \\
evaluación se debe precisamente a las dificultades que conlleva evaluar los desempeños de \\
los estudiantes en una tarea tan compleja, procesual y que involucra diferentes niveles de \\
intervención lingüística y discursiva como es la de producir textos.
\end{tabular}


Se incluyeron cuatro propuestas de evaluación de la escritura, vinculadas a los textos que los estudiantes habían leído previamente para resolver tanto ejercicios abiertos (preguntas de comprensión ligadas al texto) como cerrados (preguntas de opción múltiple). Las primeras dos actividades partieron de la lectura de textos narrativos literarios, la tercera estuvo vinculada a un texto académico expositivo y la cuarta, a un texto periodístico argumentativo. La evaluación de la escritura consistió en una indagación descriptiva y de alcance exploratorio tendiente a analizar los logros y las dificultades de los estudiantes argentinos en la apropiación de tramas expositivas y narrativas, en la construcción de la coherencia global y en el uso de reglas gramaticales de los textos que producen.

Una de las propuestas de escritura del ONE 2013 en la evaluación de alumnos de sexto año de primaria fue redactar un cuento a partir de seleccionar alguno de los personajes de un texto fantástico leído previamente. La consigna especificaba:

\begin{abstract}
Elegí uno de los siguientes personajes: monstruo, hada, gigante, dragón, bruja, vampiro. Imaginá un nombre para ese personaje, además inventale una familia, una actividad, un lugar donde viva, etc. Pensá qué conflicto o complicación se le podría presentar. ¿̇ómo lo resolvería? Organizá la historia en tres partes: una situación inicial, una complicación o conflicto y la resolución o desenlace.
\end{abstract}

Escribí el cuento.

Colocá un título atractivo.

Una vez escrito, ja revisar!: Releé el texto, asegurate de que se entiende lo que quisiste decir. Corregi, si es necesario, la ortografía y la puntuación. (DiNIECE, 2014, p. 13)

En el análisis de las producciones se contemplaron los siguientes indicadores: descripción del personaje (se selecciona uno de los personajes, se le asigna un nombre, se lo caracteriza), organización súper estructural (se respeta la estructura canónica de una narración: situación inicial, conflicto o complicación, desenlace), organización semántica/coherencia (existe unidad temática y progresión), organización sintácticaléxico-semántica/cohesión, morfosintaxis, ortografía, puntuación y legibilidad (tabla 8).

\title{
3.4. Desempeño en escritura de los alumnos argentinos de $6^{\circ}$ grado en el ONE
}

En el análisis de las producciones, el informe (DiNIECE, 2014) realiza un abordaje descriptivo de los resultados, introduciendo ejemplos que refieren a las distintas dimensiones consideradas. No se especifica el porcentaje de sujetos que se sitúa en cada uno de los niveles de desempeño.

Señala que la "mayoría" de los estudiantes de $6^{\circ}$ año logra caracterizar de modo breve el personaje siendo muy pocos los que no eligen ninguno de los personajes solicitados en la consigna.

Los alumnos respetan la estructura canónica de la narración aunque en algunos casos están desbalanceados los tres momentos (introducción, desarrollo y desenlace).

En lo referido a la organización semántica o la coherencia del texto, en general, los estudiantes mantienen la unidad temática, aunque, a veces, reiteran innecesariamente algunas ideas o incorporan detalles que no son importantes para el desarrollo de las acciones. 
Tabla 8. Descripción de las dimensiones de análisis de las producciones escritas según tres niveles de desempeño

\begin{tabular}{|c|c|c|c|}
\hline DIMENSIÓN & NIVEL 1 & NIVEL 2 & NIVEL 3 \\
\hline $\begin{array}{l}\text { Descripción del } \\
\text { personaje }\end{array}$ & $\begin{array}{l}\text { Elige uno de los personajes solicitados. Le } \\
\text { asigna un nombre. Caracteriza su familia, } \\
\text { actividad, lugar; incluye detalles y/o } \\
\text { ejemplos. }\end{array}$ & $\begin{array}{l}\text { Elige uno de los personajes solicitados. No le } \\
\text { asigna un nombre. Da por lo menos dos } \\
\text { características del personaje. }\end{array}$ & $\begin{array}{l}\text { No elige ninguno de los personajes } \\
\text { solicitados. Puede o no asignarle un } \\
\text { nombre. No caracteriza al personaje }\end{array}$ \\
\hline $\begin{array}{l}\text { Organización súper } \\
\text { estructural }\end{array}$ & $\begin{array}{l}\text { Respeta superestructura del texto narrativo. } \\
\text { Están bien balanceados los } 3 \text { momentos. }\end{array}$ & $\begin{array}{l}\text { Hay esbozo de superestructura del texto } \\
\text { narrativo. Hay introducción excesiva y } \\
\text { desbalanceada con respecto a los otros } 2 \\
\text { momentos. Plantea el conflicto, pero apresura } \\
\text { resolución. }\end{array}$ & $\begin{array}{l}\text { Solo se queda en la introducción y no } \\
\text { avanza. }\end{array}$ \\
\hline $\begin{array}{l}\text { Organización } \\
\text { semántica/ } \\
\text { coherencia }\end{array}$ & $\begin{array}{l}\text { Mantiene el tema a lo largo de todo el texto. } \\
\text { Progresión adecuada de ideas planteadas. } \\
\text { Texto sin contradicciones. }\end{array}$ & $\begin{array}{l}\text { Mantiene el tema a lo largo del texto. Si bien } \\
\text { hay progresión, se reiteran ideas; hay detalles no } \\
\text { importantes. }\end{array}$ & $\begin{array}{l}\text { No se mantiene el tema a lo largo de todo } \\
\text { el texto. Hay contradicciones, información } \\
\text { poco relacionada con el tema. }\end{array}$ \\
\hline $\begin{array}{l}\text { Organización } \\
\text { sintáctica- léxico } \\
\text { semántica/cohesión }\end{array}$ & $\begin{array}{l}\text { Realiza conexiones lógicas y usa } \\
\text { correctamente marcadores textuales. Usa } \\
\text { mecanismos de correferencia. Sustitución } \\
\text { pronominal. Sustitución por sinonimia. }\end{array}$ & $\begin{array}{l}\text { Es posible que cometa algunos errores, es capaz } \\
\text { de realizar conexiones lógicas y usar } \\
\text { correctamente marcadores textuales. Alterna } \\
\text { sustantivos y pronombres para mantener el } \\
\text { referente en un texto. Escasa sustitución por } \\
\text { sinonimia. }\end{array}$ & $\begin{array}{l}\text { Aparecen ideas yuxtapuestas o unidas por } \\
\text { relaciones de adición. Usa conectores } \\
\text { temporales de uso habitual. Aparecen } \\
\text { referencias ambiguas. }\end{array}$ \\
\hline Morfosintáctica & $\begin{array}{l}\text { Realiza la concordancia correcta en número y } \\
\text { persona; en género y número. Utiliza el } \\
\text { sistema de tiempos verbales en forma } \\
\text { pertinente. }\end{array}$ & $\begin{array}{l}\text { Realiza la concordancia correcta en número y } \\
\text { persona; en género y número. Utiliza los } \\
\text { tiempos verbales en forma pertinente. Maneja } \\
\text { algunos tiempos verbales. }\end{array}$ & $\begin{array}{l}\text { Presenta dificultades en mantener } \\
\text { concordancia y aparecen errores en el uso } \\
\text { de la morfología verbal, errores de } \\
\text { conjugación. }\end{array}$ \\
\hline $\begin{array}{l}\text { Normativa: } \\
\text { ortografía, } \\
\text { tildación, uso de } \\
\text { b,v,s,z,g, etc.. y } \\
\text { mayúsculas }\end{array}$ & $\begin{array}{l}\text { Uso correcto de la tildación (tilde diacrítica, } \\
\text { tilde en pronombres interrogativos y } \\
\text { exclamativos, ausencia de tilde en las } \\
\text { palabras con hiato } 1 \text { cada } 5 \text { ). Algunos errores } \\
\text { en el uso de s/c/z - b/v. Mayúscula en } \\
\text { abreviaturas y en tratamientos abreviados } \\
\text { (por ej. Dr., Sr.). }\end{array}$ & $\begin{array}{l}\text { Aplica las reglas generales de acentuación. Uso } \\
\text { correcto de la tildación aunque aparición de } \\
\text { mayor número de errores. Algunos errores en el } \\
\text { uso de } \mathrm{s} / \mathrm{c} / \mathrm{z}-\mathrm{b} / \mathrm{v} \text {. Mayúscula en nombres } \\
\text { propios y después de cualquier punto. }\end{array}$ & $\begin{array}{l}\text { Ausencia de tildes o uso indiscriminado. } \\
\text { Gran número de errores en el uso de } \\
\text { s/c/z - b/v. Emplea las reglas básicas de } \\
\text { nuestro sistema de escritura Usos de } \\
\text { mayúscula: al principio de oraciones y } \\
\text { párrafos. }\end{array}$ \\
\hline Puntuación & $\begin{array}{l}\text { Emplea signos de puntuación: algunas } \\
\text { convenciones sobre el uso de las comas: coma } \\
\text { para la aclaración y para la aposición. }\end{array}$ & $\begin{array}{l}\text { Signos de puntuación: algunas convenciones } \\
\text { sobre el uso de las comas. Usa dos puntos y raya } \\
\text { de diálogo. }\end{array}$ & $\begin{array}{l}\text { Signos de puntuación: punto y aparte, uso } \\
\text { de la coma en enumeración. Signos de } \\
\text { interrogación y exclamación. } \\
\end{array}$ \\
\hline
\end{tabular}


Se señala que resulta significativa la cantidad de errores ortográficos en las producciones. $\mathrm{El}$ informe retoma lo especificado por el SERCE (Atorresi et al., 2010) que plantea que los alumnos que demuestran un buen manejo de la ortografía poseen mayor conciencia metalingüística, lo que se evidenciaría, por ejemplo, en un mejor desempeño en la coherencia de sus producciones escritas, a diferencia de los estudiantes que presentan un rendimiento ortográfico más bajo.

La ortografía, considerada en un estadio inicial, es incluida en el TERCE dentro de la dimensión de condiciones de legibilidad. En cambio en el ONE, ambas dimensiones aparecen diferenciadas y la legibilidad se centra en el tipo de letra utilizada y en las hipo e híper segmentaciones.

La escritura de los estudiantes es considerada, en su mayoría clara y la lectura resultó sencilla, aunque, en algunos casos, se dificultó por la alternancia de mayúsculas y minúsculas de imprenta. Hubo pocos textos ilegibles, coincidentes con el empleo de la cursiva. En el sistema educativo argentino se observa un uso preferencial de la letra imprenta mayúscula en los estadios iniciales del proceso de alfabetización, tanto para la lectura como para la escritura, y cierta dificultad en el dominio, ya sea simultaneo y/o progresivo, de otros tipos de letras. De alguna manera, esto puede considerarse contradictorio con los lineamientos que enfatizan el uso social de la escritura. Hace muchos años la letra imprenta minúscula fue adoptada como la habitual en los textos impresos ya que favorece la lectura debido a la mayor cantidad de rasgos que permiten discriminar una letra de otra y la importancia de la mayúscula en los textos. Por otra parte, la letra cursiva ofrece ventajas al escribir ya que supone una velocidad de trazo mucho mayor a la vez que promueve habilidades de autocontrol (Borzone y Marder, 2015).

El ONE incluye en el análisis de los resultados la consideración de algunas marcas de reescritura, las que vincula a los procesos de planificación y revisión. En algunos de los textos producidos fue posible observar tachaduras, borrones o el señalamiento de los tres momentos de la narración como indicio de la preocupación de algunos alumnos por responder a la consigna. También en otros casos se observó que aparecía una primera versión y luego la considerada como definitiva. Esto se puede vincular al uso de borradores como estrategia para favorecer los procesos antes señalados, lo que explícitamente se incorporaba a la consigna de escritura del SERCE.

La mayoría coloca el título solicitado. Además el 80\% coloca la palabra "Fin" al terminar su texto. Esto se asocia en el análisis a cierta práctica escolar arraigada que tal vez se ligue al cartel que aparece en algunos libros y/o películas infantiles.

Por último, se menciona que en las producciones de los escritos los niños dan muestran de recurrir a otros textos a la hora de inspirarse para desarrollar el tema propuesto en la consigna de evaluación. Se rastrean así variadas fuentes (personajes de la literatura, de series, de video juegos, entre otros).

Es importante recordar que la evaluación de la escritura se realizó en el ONE 2013 luego de la lectura de un cuento fantástico. A partir de la lectura se planteaba la consigna de escritura pero también se formulaba una pregunta abierta relativa al género textual. Muchos estudiantes respondieron la pregunta abierta sobre la definición del género fantástico en forma correcta. Sin embargo, en las producciones realizadas por los estudiantes se pudo observar que más que escribir ellos mismos un texto de estas 
características optaron por el cuento tradicional o maravilloso, lo que puede vincularse a las prácticas escolares habituales.

\section{Discusión y conclusiones}

En este apartado final se retomará lo analizado a lo largo del artículo al tiempo que se incluyen tres cuestiones consideradas relevantes. Por un lado, se presenta un breve análisis comparativo de la evaluación de la escritura a la finalización de la escolaridad primaria en el TERCE y en el ONE. Si bien ambos operativos exploran la producción escrita de textos en sus últimas ediciones, no lo hacen de modo análogo. Esto no implica desconocer que, en la medida en que el TERCE parte del análisis curricular de los países participantes, ambos estudios comparten algunos aspectos comunes de importancia. Por otro lado, se incorporan algunas reflexiones vinculadas a los núcleos de aprendizaje prioritarios y a los diseños curriculares desarrollados en Argentina en los últimos años (NAP, 2005). Asimismo, se hará una breve referencia a la formación docente en alfabetización en dicho país.

Ambas evaluaciones deben inscribirse en la preocupación contemporánea por la calidad de la educación. Consideran que los logros en el aprendizaje constituyen un elemento central en el abordaje de la calidad educativa al tiempo que reconocen que también otros indicadores deben contemplarse en su abordaje. La tabla 9 presenta un cuadro comparativo sintético de ambos operativos. Nos interesa, tal como fuera previamente mencionado, retomar aquí fundamentalmente algunas cuestiones relativas a la enseñanza y la evaluación de la escritura.

El análisis curricular realizado por el TERCE releva la importancia en los sistemas educativos de la región de un enfoque funcional y comunicativo de la escritura. En consonancia con esto, documentos curriculares en Argentina delimitan el área encargada de la enseñanza de la lectura y la escritura como "Prácticas del lenguaje". Parten de definir como "prácticas del lenguaje a las diferentes formas de relación social que se llevan a cabo por medio, en interacción y a partir del lenguaje. Lo que se enseñará es, pues, el dominio práctico del lenguaje en el marco de las situaciones sociales reales" (DGCyE, 2008, p. 93). En función de ello privilegian como objeto de enseñanza las prácticas mismas -hablar y escuchar, leer y escribir- sobre los contenidos lingüísticos escolares, es decir, la apropiación de las prácticas en situaciones con sentido. Se sugieren para ello tres situaciones: el ámbito de la literatura, el de estudio y el de la formación del ciudadano y se otorga importancia a la reflexión sobre el lenguaje. Es decir, que los niños, en la educación primaria, a partir de participar en situaciones de lectura y escritura significativas, construyen conocimiento sobre el sistema alfabético y las correspondencias grafofónicas. La intervención docente es indirecta y apunta a promover la realización de anticipaciones e inferencias respecto de cómo funciona el sistema.

Si bien resulta sumamente interesante la propuesta apuntada, sobre todo en lo atinente al interés en promover situaciones contextualizadas y que resulten significativas para los alumnos, desde otras aproximaciones se ha señalado la importancia de la enseñanza explícita y temprana del principio alfabético, es decir, de las correspondencias entre grafemas y fonemas. 
Tabla 9. Comparación del TERCE y el ONE con foco en la evaluación de la producción escrita

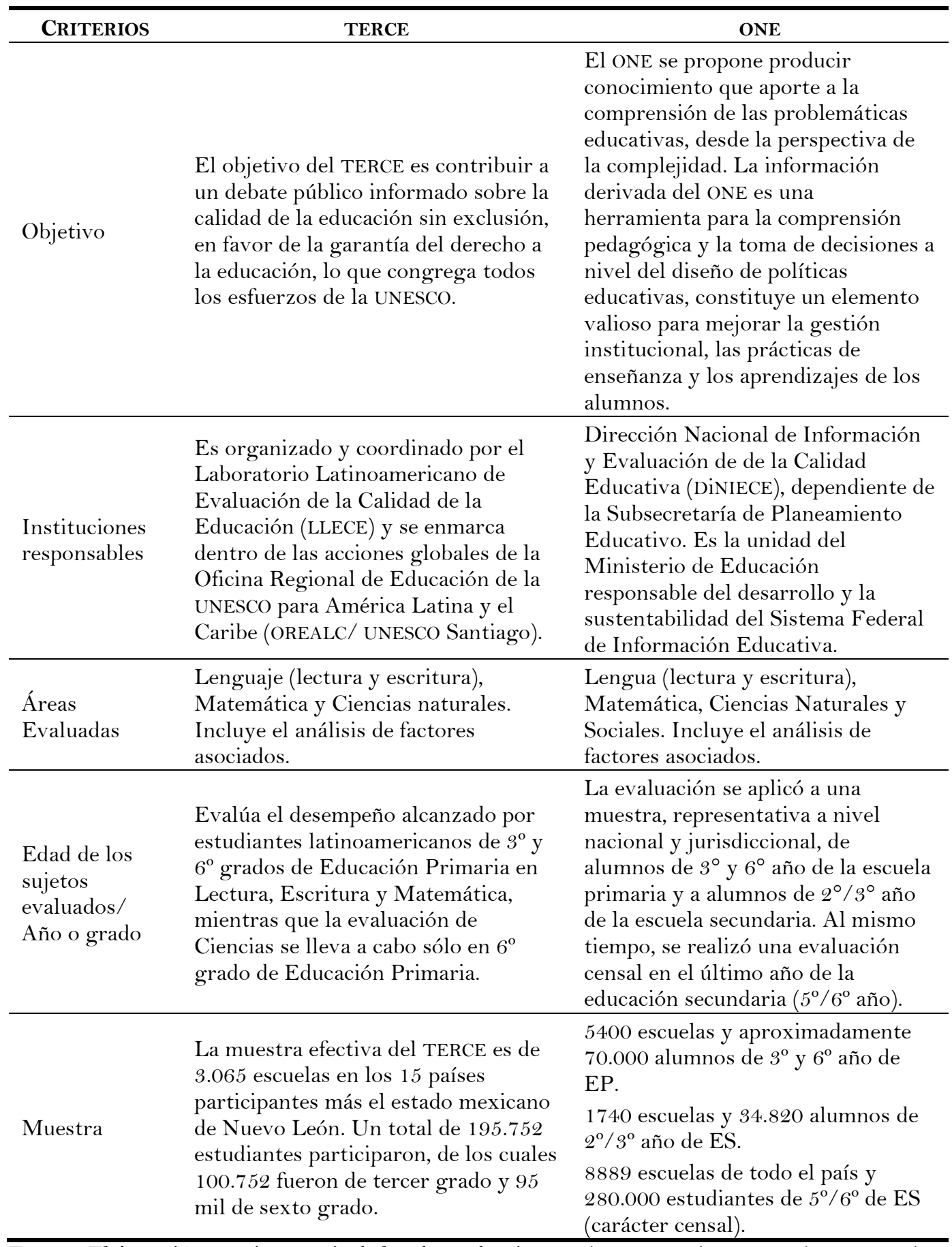

Fuente: Elaboración propia a partir de los datos de DiNIECE (2010, 2014); UNESCO (2010, 2015). 
Tabla 9 bis. Comparación del TERCE y el ONE con foco en la evaluación de la producción escrita. Continuación

\begin{tabular}{|c|c|c|}
\hline CRITERIOS & TERCE & ONE \\
\hline $\begin{array}{l}\text { Enfoque sobre } \\
\text { la escritura }\end{array}$ & $\begin{array}{l}\text { El enfoque de evaluación de escritura } \\
\text { se basa en la perspectiva curricular de } \\
\text { los países participantes en el estudio. } \\
\text { Se enfatiza el uso funcional del } \\
\text { lenguaje en situaciones comunicativas } \\
\text { concretas. Por esto se considera la } \\
\text { producción de diferentes tipos de } \\
\text { texto y géneros según el propósito y } \\
\text { la situación comunicativa, } \\
\text { privilegiando la capacidad del } \\
\text { estudiante para producir sentido y } \\
\text { comunicar en forma coherente sus } \\
\text { ideas. También se considera la } \\
\text { estructuración interna de los textos y } \\
\text { aspectos formales como la ortografía, } \\
\text { la caligrafía, entre otros. Se retoma la } \\
\text { distinción entre texto y discurso. }\end{array}$ & $\begin{array}{l}\text { Se caracteriza nuestro sistema de } \\
\text { escritura alfabético como un sistema } \\
\text { organizado para representar sonidos } \\
\text { a través de formas gráficas. Se } \\
\text { define la escritura como práctica } \\
\text { social y se enfatiza la importancia de } \\
\text { la situación comunicativa. También } \\
\text { se reconoce que es una práctica } \\
\text { individual, un proceso cognitivo } \\
\text { ligado a la resolución de un } \\
\text { problema. Se retoma la diferencia } \\
\text { entre oralidad y escritura y entre } \\
\text { lectura y escritura. Se retoman los } \\
\text { procesos de escritura: planificación, } \\
\text { textualización y revisión como } \\
\text { recursivos. }\end{array}$ \\
\hline
\end{tabular}

La rúbrica de evaluación se estructura en tres dimensiones, cada una de las cuales considera dos o tres indicadores específicos.

1. Dimensión discursiva: a)

Grilla/rúbrica de evaluación

Propósito, secuencia y adecuación a la consigna; b) Género.

2. Dimensión textual: a) Coherencia global; b) Concordancia; c) Cohesión.

3. Dimensión convenciones de legibilidad: a) Ortografía literal inicial; b) Segmentación de palabras; c) Puntuación.

Se organiza en tres secciones de información. 1. Puntuaciones medias de cada país y variabilidad respecto del promedio de los países

Análisis y presentación de los resultados participantes. Se utiliza una escala de 1 a 4 puntos asociada a diferentes niveles de desempeño. 2. Promedio de cada país en cada dimensión o dominio. 3. Análisis de los niveles de desempeño de los países en cada dimensión.
Se elaboró una grilla de corrección que incluye las siguientes dimensiones de análisis de las producciones: descripción del personaje, organización superestructural, organización semántica / coherencia, organización sintáctica-léxicosemántica/cohesión, morfosintaxis, ortografía, puntuación y legibilidad.

En la presentación de los resultados se realiza un análisis descriptivo del desempeño de los estudiantes en cada una de las dimensiones especificadas y se presentan ejemplos de producciones escritas. Se delimitan para cada una de las dimensiones tres niveles de desempeño pero no se menciona qué porcentaje de sujetos de la muestra se sitúa en cada uno de ellos.

Fuente: Elaboración propia a partir de los datos de DiNIECE (2010, 2014); UNESCO (2010, 2015).

Se considera que el conocimiento de tales correspondencias es central para el acceso a una lectura y escritura fluidas, las que constituyen condiciones necesarias, aunque no suficientes, para la comprensión y producción de textos, considerados procesos de nivel superior implicados en la construcción de significado (McCardle y Chhabra, 2004; National Reading Panel, 2000; Snow, Griffin y Burns, 2005). 
Tal como señala Piacente (2009):

Obviamente el lenguaje escrito no se reduce al sistema de escritura, que asimismo involucra otros aspectos complejos como los referidos a las marcas extra alfabéticas (por ejemplo, los signos de puntuación, el tratamiento de los espacios en blanco, la ortografía, el reconocimiento de los diferentes alógrafos, entre otros). Involucra además el tipo de 'estilo' particular que lo caracteriza, que se plasma en los diferentes géneros y tipos textuales y en los usos particulares que conllevan. (p. 139)

El "contexto de producción" es un aspecto importante, considerado tanto en los modelos teóricos, en los diseños curriculares como en los operativos de evaluación objeto de análisis. El TERCE incluye en su fundamentación la distinción entre texto y discurso que separa la dimensión estructural del texto de su dimensión relacional, es decir, la consideración de la situación comunicativa y el contexto (UNESCO, 2015). Snow y Uccelli (2009) proponen cuatro dimensiones planteadas como desafíos de la producción textual en cualquier evento comunicativo: la representación de si mismo y de la audiencia y la representación del mensaje, que se vinculan a lo discursivo, por un lado, y la organización del discurso y la construcción de oraciones ligadas a lo textual, por otro.

Quiere señalarse aquí que el aprendizaje de la escritura de textos conlleva particulares dificultades debido al conjunto de niveles o dimensiones que se encuentran implicados y que deben ser considerados en los procesos de enseñanza y de evaluación, intentando evitar acentuar excesivamente unos por sobre otros (Zabaleta, 2015).

Un desafío importante tanto para los ámbitos académicos de producción de conocimiento como para los operativos de evaluación de los aprendizajes, enmarcados en la preocupación por la calidad educativa, refieren a su impacto real en un nivel generalmente olvidado por las políticas educativas, que es el de la enseñanza áulica. La enseñanza no puede ser considerada solo un problema instrumental sino fundamentalmente un problema político ligado, entre otras cuestiones, a las acciones concretas que pueden realizar los docentes a partir de la formación recibida y en el marco de ciertas condiciones institucionales de escolarización (Baquero, Tenti Fanfani y Terigi, 2004).

La formación docente en Argentina se realiza en Institutos Superiores que pertenecen al Nivel de Educación Superior (no universitario). Constituye uno de los cuatro niveles, conjuntamente con el Inicial, Primario y Secundario, en que se estructura el sistema educativo argentino. La formación docente tiene la finalidad de:

preparar profesionales capaces de enseñar, generar y transmitir los conocimientos y
valores necesarios para la formación integral de las personas, el desarrollo nacionaly
la construcción de una sociedad más justa. Promoverá la construcción de una
identidad docente basada en la autonomía profesional, el vínculo con la cultura y la
sociedad contemporánea, el trabajo en equipo, el compromiso con la igualdad y la
confianza en las posibilidades de aprendizaje de los/as alumnos/as. (Art. 71 y 72 ,
Ley de Educación Nacional, 2006)

En este sentido la Ley considera a la formación docente como factor clave del mejoramiento de la educación (Zabaleta y Piatti, 2010). Una novedad que introduce la Ley Nacional de Educación se liga a la creación del Instituto Nacional de Formación Docente (INFoD), dependiente del Ministerio de Educación de la Nación. Corresponde a este instituto entre otras tareas la de planificar y ejecutar políticas de articulación del sistema de formación docente y promover los lineamientos curriculares básicos para la formación docente. El INFoD durante los años 2008 y 2009 llevó a cabo un estudio nacional sobre la 
formación docente en alfabetización. Se considera la temática como área de vacancia y se destaca su relevancia en tanto que:

\begin{abstract}
la institución escuela ha asumido históricamente la responsabilidad pedagógica de enseñar a leer y escribir y por ello la necesaria formación del rol alfabetizador del maestro es responsabilidad pedagógica del sistema formador. Sin embargo, en las carreras que forman profesores para la escuela primaria no existen acuerdos explícitos acerca de quiénes son los responsables directos de dicha formación de modo tal que el rol alfabetizador del docente no es reconocido y asumido en la práctica como un aspecto central de la carrera. (Zamero, 2010, p. 9)
\end{abstract}

El consenso de numerosos trabajos de investigación gira en torno de la necesidad de formar docentes con amplios conocimientos sobre el lenguaje y la alfabetización. Sin embargo, en los cursos específicos no siempre se presta atención adecuada a las cuestiones referidas a la particular estructura del lenguaje, en especial del lenguaje escrito y sobre cómo los niños lo aprenden (Cook-Moats, 2010).

La indagación realizada en el presente artículo impulsa a la reflexión acerca de cuestiones centrales en la perspectiva de la alfabetización del siglo XXI. Las diferencias individuales en los puntos de partida en el proceso de alfabetización inicial y posterior ponen de relieve experiencias de distinto tenor según los contextos de procedencia familiar y escolar, que de no ser tenidas en cuenta obstaculizan la progresión de los aprendizajes. El TERCE plantea como uno de los desafíos, la reducción de las desigualdades no solo entre países sino al interior de los mismos. Argentina ha obtenido buenos resultados en la evaluación de la producción escrita de textos pero persisten amplias diferencias entre los sujetos con alto y bajo desempeño. La inclusión para una alfabetización exitosa, debe contemplar estrategias de enseñanza específicas a partir de la consideración de las evidencias que aportan las investigaciones sobre la lectura y la escritura y los operativos de evaluación de los aprendizajes. Tales evidencias no siempre logran trascender los circuitos académicos, instaurándose una brecha entre ellos y la práctica educativa. En otros casos, si bien han recibido atención de parte de las autoridades educativas, no logran plasmarse en el diseño de intervenciones exitosas frente a los desafíos actuales de la enseñanza del lenguaje escrito, considerado una de las competencias imprescindibles no sólo para el éxito en el trayecto formativo sino también a lo largo de toda la vida, teniendo en cuenta las demandas progresivas en materia de alfabetización en una sociedad altamente letrada.

\title{
Becas, ayudas o soporte financiero:
}

El trabajo se ha realizado a partir de Becas de Iniciación otorgadas por la Comisión de Investigaciones Científicas de la Provincia de Buenos Aires y por el soporte financiero otorgado por la Secretaria de Ciencia y Técnica de la Universidad Nacional de La Plata.

\section{Referencias}

Atorresi, A (2005). Competencias para la vida en las evaluaciones de lectura y escritura (SERCE LLECE). OREALC/LLECE.

Atorresi, A., Bengochea, R., Bogoya, D., Burga, A., Castro, M., Garcia, F., .., Pardo, C. (2010). Escritura. Un estudio de las habilidades de los estudiantes de América latina y el Caribe. Santiago: UNESCO-OREALC. 
Baddeley, A. D. y Hitch, G. J. (1974). Working memory. En G. Bower (Ed.), The psychology of learning and motivation (pp. 47-90). Nueva York: Academic Press.

Bajtín, M. (1982). Estética de la creación verbal. México: Siglo XXI.

Baquero, R., Tenti Fanfani, E. y Terigi, F. (2004). Educabilidad en tiempos de crisis. Condiciones sociales y pedagógicas para el aprendizaje escolar. Novedades Educativas, 168, 18-31.

Bereiter, C. y Scardamalia, M. (1987). The pschology of written communication. Hillsdale, NJ: Erlbaum.

Borzone, A. M. y Marder, S. (2015). Leamos juntos. Programa para la enseñanza y el aprendizaje de la lectura y la escritura. Buenos Aires: Paidós.

Cook-Moats, L. (2010). Speech to Print. Language. Essentials for teachers. Baltimore, MD: Paul H. Brookes.

Chenoweth, A. y Hayes, J. (2001). Fluency in writing: generating text in L1 and L2. Written Communication 18, 80-98. doi:10.1177/0741088301018001004

DGCyE. (2008). Diseño curricular para la educación primaria. Segundo ciclo. La Plata: Dirección General de Cultura y Educación.

DiNIECE. (2001). Documentos metodológicos. Glosario. Recuperado de http://diniece.me.gov.ar/

DiNIECE. (2003) Informe resultados ONE 2003. Recuperado de http://diniece.me.gov.ar/

DiNIECE. (2010).Operativo nacional de evaluación 2010. $3^{\circ}$ y $6^{\circ}$ año de la Educación Primaria. Informe de resultados.. Recuperado de http://diniece.me.gov.ar/

DiNIECE. (2014). Informe diagnóstico de producción escrita. Un itinerario: de la consigna a la grilla. ONE 2013. Recuperado de: http://diniece.me.gov.ar/

Fayol, M. (2007). La production de textes et son apprentissage. Recuperado de www.inrp.fr/ONL

Gathercole, S. E. y Baddeley, A. D. (1993). Working memory and language. Hove: Erlbaum.

Gombert, J. E. (1990). Développement métalinguistique et langage écrit. En E. Gombert (Dir.), Le développement métalinguistique (pp. 197-225). París: Presses Universitaires du France.

Gombert, J. E. (1992). Actividades de lectura y actividades asociadas. En M. Fayol, J. E. Gombert, P. Lecocq, L. Sprenger-Charolles y D. Zagar (Eds.), Psychologie cognitive de la lectura (pp.107140) París: Presses Universitaires de France.

Hayes, J. R. (1996). A new framework for understanding cognition and affect in writing. En C. M. Levy y S. Ransdell (Eds.), The science of writing: theories, methods, individual differences and application (pp. 1-27). Mahwah, NJ: Erlbaum.

Hayes, J. R. (2004). What triggers revision? En L. Allal, L. Chanquoy y P. Largy (Eds.), Studies in writing. Revision: cognitive and instructional processes (pp. 9-20). Norwell, MA: Kluwer.

Hayes, J. R. (2006). New directions in writing theory. En C. A. MacArthur, S. Graham y J. Fitzgerald (Eds.), Handbook of writing research (pp. 28-40). Nueva York: The Guilford Press.

Hayes, J. R. y Flower, L. (1981). Identifying the organization of writing processes. En L. W. Gregg y E. R. Stemberg (Comp.), Cognitive processes in writing (pp.3-30). Hillsdale, NJ: Erlbaum.

Jaffré, J. P. (1988). Lecture et production graphique chez les jeunes enfants. L'exemple du domain extralphabétique. Langue Françaises, 80, 20-32. doi:10.3406/lfr.1988.4758

Jaffré, J. P. (1996). Grafemas e ideografía. Enfoque psicolingüístico de la noción de grafema. En N. Catach (Comp.), Hacia una teoría de la lengua escrita (pp. 119-132). Barcelona: Gedisa. 
Kellogg, R. T. (1999). Components of working memory in text production. En M. Torrance y G. C. Jeffery (Eds.), The cognitive demands of writing. Processing capacity and working memory in text production (pp. 42-61). Amsterdam: Amsterdam University Press.

McCardle, P. y Chhabra, V. (2004). The voice of evidence in reading research. Baltimore: P. H. Brookes Publishing Co.

McCutchen, D. (2006). Cognitive factors in the development of children's writing. En C. A. MacArthur, S. Graham y J. Fitzgerald (Eds.), Handbook of writing research (pp. 115-130). Nueva York: The Guilford Press.

Molinari Marotto, C. (1996). Introducción a los modelos cognitivos de la comprensión del lenguaje. Buenos Aires: Eudeba.

National Reading Panel (2000). Report of the national reading panel. Washington, DC: National Institute of Child Health and Human Development.

NAP. (2005). Núcleos de Aprendizaje Prioritarios. $2^{\circ}$ Ciclo de EGB / Nivel Primario. $4^{\circ}, 5^{\circ}$ y $6^{\circ}$ años. Buenos Aires: Ministerio de Educación, Ciencia y Tecnología.

Olson, D. (1997). El mundo sobre el papel. El impacto de la escritura y la lectura en la estructura del conocimiento. Barcelona: Gedisa.

Piacente, I. T. (2009). Especificidad de la evaluación psicológica en los procesos de aprendizaje del lenguaje escrito. Evolución y estado actual. Revista Iberoamericana de Diagnóstico y Evaluación Psicológica, 28(2), 135-148.

Piacente, I. T. (2012). Alfabetización inicial y alfabetización académica. Investigación y evaluación de los procesos implicados en el aprendizaje del lenguaje escrito. Revista Iberoamericana de Diagnóstico y Evaluación Psicológica, 33(1), 9-30.

Querejeta, M. (2007). Hipo e hipersegmentación lexical en la escritura de niños en diferentes niveles educativos. Comunicación presentada en las XIV Jornadas de Investigación y Tercer Encuentro de Investigadores en Psicología del Mercosur. Facultad de Psicología. Universidad de Buenos Aires, Buenos Aires.

Sánchez Abchi, V. S. y Borzone, A. M. (2010) Enseñar a escribir textos: desde los modelos de escritura a la práctica en el aula. Lectura y Vida, 31(1), 40-49.

Silvestri, A. (2001). La adquisición discursivo cognitiva en la escuela secundaria. Habilidades de reformulación y estrategias de memoria (Tesis doctoral). Facultad de Filosofía y Letras. Universidad de Buenos Aires, Buenos Aires.

Snow, C. y Uccelli, P. (2009). The challenge of academic language. En D. Olson y N. Torrance (Eds.). The Cambridge handbook of literacy (pp. 112-133). Nueva York: Cambridge University Press

Snow, C., Griffin, P. y Burns, M. S. (2005). Knowledge to support the teaching of reading. Preparing teachers for changing world. San Francisco, CA: Wiley \& Sons

Vigotsky, L. (1995). Pensamiento y lenguaje. Barcelona: Paidós.

Vigotsky, L. (2006). El desarrollo de los procesos psicológicos superiores. Barcelona: Crítica.

UNESCO. (2007). Educación de calidad para todos: un asunto de derechos humanos. Santiago: $\mathrm{EPT} / \mathrm{PRELAC}$.

UNESCO. (2010). Escritura: un estudio de las habilidades de los estudiantes de América Latina y el Caribe. Santiago: OREALC/UNESCO - LLECE.

UNESCO. (2013a). Análisis curricular. Santiago: OREALC/UNESCO - LLECE. 
UNESCO. (2013b). Segundo Informe Mundial sobre el Aprendizaje y la Educación de Adultos. Repensar la Alfabetización. Hamburgo: Institute for Life long Learning.

UNESCO. (2015). Informe de resultados TERCE. Logros de aprendizaje. Santiago: OREALC/UNESCO - LLECE.

Zabaleta, V. (2015). Los cambios en la lectura y la escritura en dos tramos del trayecto formativo (Tesis doctoral). Recuperada de http://sedici.unlp.edu.ar/

Zabaleta, V. y Piatti, V. (2010). Algunas consideraciones acerca de la inserción del profesor de psicología en la formación docente. Comunicación presentada en el I Congreso Internacional, II Nacional, II Regional de Psicología. Facultad de Psicología. Universidad Nacional de Rosario.

Zamero, M. (2010). La formación docente en alfabetización inicial como objeto de investigación. El primer estudio nacional. Bueno Aires: INFoD.

\section{Breve CV de los autores}

\section{Verónica Zabaleta}

Es Doctora en Psicología, Especialista en Psicología Educacional con orientación en los procesos de aprendizaje del lenguaje escrito y sus trastornos, Licenciada y Profesora en Psicología (Universidad Nacional de La Plata). Es Profesora Adjunta Ordinaria de la asignatura Psicología Educacional y Jefa de Trabajos Prácticos Ordinaria de la asignatura Psicología II (Facultad de Psicología, UNLP). Se desempeña como docente en un Instituto Superior de Formación Docente y Técnica (DGCyE, Buenos Aires). Ha sido becaria en organismos de investigación científica (CIC - CONICET, Argentina). Ha integrado proyectos de investigación acreditados y, actualmente, dirige el proyecto "Programas de intervención en comprensión lectora y prácticas de enseñanza al inicio de la escolaridad secundaria" (PPID So11, SECyT-UNLP). Es coordinadora del Área Educacional del Centro de Extensión de Atención a la Comunidad (Facultad de Psicología, UNLP). Email: veronicazabaleta@gmail.com

\section{Luis Ángel Roldán}

Es Profesor en Psicología (Universidad Nacional de La Plata). Es becario doctoral en la Comisión de Investigaciones Científicas, Provincia de Buenos Aires (Argentina). Se desempeña como Ayudante Diplomado en la cátedra Psicología II y en el Curso de Ingreso a las Carreras de Psicología (Facultad de Psicología, UNLP). Es integrante del proyecto de investigación "Programas de intervención en comprensión lectora y prácticas de enseñanza al inicio de la escolaridad secundaria” (PPID So11, SECyT-UNLP). Es coordinador de campo de la actividad de extensión "Construcción de un sistema de actividad para el aprendizaje de la comprensión de textos" dependiente del Área Educacional del Centro de Extensión de Atención a la Comunidad (Facultad de Psicología, UNLP). Email: angelroldan1990@gmail.com 


\section{María Eugenia Centeleghe}

Es Licenciada en Psicología (Universidad Nacional de La Plata). Es becaria doctoral en la Comisión de Investigaciones Científicas, Provincia de Buenos Aires (Argentina). Actualmente se encuentra cursando el Doctorado en Psicología en la Facultad de Psicología de la Universidad Nacional de La Plata, bajo la dirección de la Dra. Verónica Zabaleta. El tema de estudio es "La comprensión lectora a través de la interacción lingüística en la educación secundaria”. Es becaria-tesista del proyecto de investigación "Programas de intervención en comprensión lectora y prácticas de enseñanza al inicio de la escolaridad secundaria" (PPID So11, SECyT-UNLP). Se desempeña como docente en un Instituto Superior de Formación Docente y Técnica (DGCyE, Buenos Aires).Se desempeña como Graduada Extensionista en el Proyecto de Extensión "Las trayectorias escolares en la educación secundaria técnica” (Secretaria de Extensión, UNLP). Email: eugesol_22@hotmail.com 